\section{Flower Bud Density Affects Vegetative and Fruit Development in Field-grown Southern Highbush Blueberry}

\author{
B.E. Maust ${ }^{1}$, J.G. Williamson, and R.L. Darnell \\ Department of Horticultural Sciences, University of Florida, Gainesville, \\ FL 32611-0690
}

Additional index words. bud removal, budbreak, fruit ripening, leaf area, leaf : fruit ratio, pruning, Vaccinium corymbosum

\begin{abstract}
Floral budbreak and fruit set in many southern highbush blueberry (SHB) cultivars (hybrids of Vaccinium corymbosum $\mathrm{L}$. with other species of Vaccinium) begin prior to vegetative budbreak. Experiments were conducted with two SHB cultivars, 'Misty' and 'Sharpblue', to test the hypothesis that initial flower bud density (flower buds/ $m$ cane length) affects vegetative budbreak and shoot development, which in turn affect fruit development. Flower bud density of field-grown plants was adjusted in two nonconsecutive years by removing none, one-third, or two-thirds of the flower buds during dormancy. Vegetative budbreak, new shoot dry weight, leaf area, and leaf area : fruit ratios decreased with increasing flower bud density in both cultivars. Average fruit fresh weight and fruit soluble solids decreased in both cultivars, and fruit ripening was delayed in 'Misty' as leaf area : fruit ratios decreased. This study indicates that because of the inverse relationship between flower bud density and canopy establishment, decreasing the density of flower buds in SHB will increase fruit size and quality and hasten ripening.
\end{abstract}

Reproductive development is often an exhaustive process that affects the whole plant, as the demand for carbohydrates by reproductive organs can be high (Murneek, 1926). Fruit photosynthesis may provide a portion of the carbohydrates needed for fruit growth (Birkhold et al., 1992), but most of the carbohydrates come from current leaf photosynthesis or storage reserves. If carbohydrate supplies are insufficient to meet the demands of the different reproductive and/or vegetative sinks, competition occurs and sink development is affected. For example, reduced vegetative development is associated with fruiting in tomato (Lycopersicon esculentum L.) (Hurd et al., 1979; Murneek, 1926), apple (Malus $\times$ domestica Borkh.) (Avery etal., 1979; Maggs, 1963), cherry (Prunus avium L.) (Kappel, 1991), and strawberry (Fragaria ×ananassa Duchesne) (Schaffer et al., 1986).

In many crops, vegetative development precedes floral budbreak and fruit set. For example, inflorescences in strawberry and tomato arise from the axils of leaves after the canopy has partially developed. In northern highbush blueberry (Vaccinium corymbosum L.), vegetative budbreak precedes floral budbreak (Bell, 1950), and in apple 18\% to $20 \%$ of the total canopy present at harvest is

Received for publication 1 July 1998. Accepted for publication 16 Oct. 1998. Florida Agricultural Experiment Station, Journal Series no. R-06565. The cost of publishing this paper was defrayed in part by the payment of page charges. Under postal regulations, this paper therefore must be hereby marked advertisement solely to indicate this fact.

${ }^{1}$ Current address: Centro de Investigaciónes Cientificas de Yucatán, A.P. 87, Cordemex, Yucatán, Mexíco. present during full bloom (Forshey et al., 1983). However, in many southern highbush blueberry (SHB) cultivars, floral budbreak and fruit set begin prior to vegetative budbreak. Field observations in Floridaindicate that heavy flower and fruit loads in some SHB cultivars may delay and reduce vegetative budbreak and canopy development. Partial removal of some of these flower buds by shoot tip pruning increases vegetative budbreak and shoot development, supporting the field observations. Thus, flower and fruit load appear to have a significant effect on vegetative budbreak and subsequent shoot development in SHB. The reduction in canopy development associated with high flower and fruit load would reduce leaf area : fruit ratios and could reduce fruit yield. However, the effect of flower and fruit load on vegetative budbreak, shoot development, and leaf area : fruit ratios, and the effect of leaf area : fruit ratios on fruit development have not been studied in SHB.

The present study tests the following hypothesis: as initial flower bud and fruit density decrease in SHB, the extent of vegetative budbreak and canopy development increase, which in turn enhances fruit development. The specific objectives were to determine the effects of 1) varying flower bud densities on vegetative budbreak and canopy development; and 2) leaf area : fruit ratio on fruit weight, quality, and development period.

\section{Materials and Methods}

Experiments were conducted at the Horticultural Research Unit near Gainesville, Fla., SHB plants, and in 1997 using 10 'Misty' plants. These cultivars were chosen because of their differing spring budbreak phenologies. in 1995 using 10 'Misty' and 10 'Sharpblue'
In 'Sharpblue', vegetative and floral buds break simultaneously, while in 'Misty', vegetative budbreak occurs up to 4 weeks after floral budbreak. The plants were 5-7 years old and were planted $0.8 \mathrm{~m}$ apart in a single row oriented north-south. Soil type was a Kanapaha fine sand (loamy, siliceous, hyperthermic, Grossarenic, Paleudults) amended with peat at the rate of $38 \mathrm{~m}^{3} \cdot \mathrm{ha}^{-1}$. The strip of soil extending $0.8 \mathrm{~m}$ on each side of the row was covered with a 8-12-cm layer of pine bark mulch. Plants were fertilized with $9.2 \mathrm{~kg} \cdot \mathrm{ha}^{-1}$ per month of granular $16 \mathrm{~N}-2 \mathrm{P}-7 \mathrm{~K}$ fertilizer. Irrigation and weed control practices followed standard recommendations (Williamson and Lyrene, 1995).

Three healthy canes of average vigor and flower bud density were selected on most plants; however, some plants had only two suitable canes. In those cases, an additional cane was selected on an adjacent plant to complete the replication. The following treatments were randomly assigned to the three selected canes per replication: 1) no flower buds removed; 2) every third flower bud removed; 3 ) every second and third flower bud removed. Flower buds were hand thinned during dormancy (Feb. 1995 and Jan. 1997) at evenly spaced intervals along the canes instead of at the cane tips, to separate the possible effects of apical dominance from those of flower bud density. The canes not selected for the experiment were allowed to flower and fruit with no flower bud adjustment.

In 1995, canes were 1-3 years old and total cane length, including lateral shoots and all wood ages, averaged $320 \mathrm{~cm}$ (range from 112$642 \mathrm{~cm}$ ). In 1997, canes were 1 year old and averaged $85 \mathrm{~cm}$ in length (range from 33-175 $\mathrm{cm})$. Prior to flower bud thinning, length of each treatment cane, including lateral stems, was measured from the point of attachment to the subtending cane, and the total number of flower buds per cane was counted. Initial flower bud density (flower bud number $/ \mathrm{m}$ cane length) was determined.

Floral and vegetative budbreak on the treated canes was measured on a weekly basis and ripe fruits were harvested every 3-5 d. Fruit development period (FDP) was calculated as the number of days from $80 \%$ full bloom to $80 \%$ ripe fruit. Fruit soluble solids were measured (1995 only) on a subsample of five fruits from each cane at each harvest date with an Abbe refractometer (model 10460; Cambridge Instrument, Buffalo, N.Y.). Treatment canes were removed after final fruit harvest. Leaf area was measured using a LICOR portable leaf area meter (model LI-3000; LI-COR, Lincoln, Nebr.) and the leaves and current-year's stems were dried at $70{ }^{\circ} \mathrm{C}$ to determine dry weight.

The experimental design was a randomized complete-block design with 10 replications, considering the degree of flower bud thinning as the treatment, and individual plants, or in some cases two adjacent plants, as blocks. The plants were nested within the two cultivars in 1995 and all plants within a cultivar were in the same section of a row. Repeated measures over time were observed on individual canes, which were nested within indi- 
vidual blueberry plants. The SAS program (SAS Institute, Cary, N.C.) was used for statistical analyses. Flower bud density varied over wide ranges for each of the three treatments; these data were therefore analyzed with regression as a continuous, rather than a discrete, variable. PROC GLM was used for analysis of variance and regression analysis and PROC CORR was used to test correlations. Variability among plants was not statistically significant, so plant effects were not used in the model. Total cane length was used as a covariate to account for differences in initial cane size.

\section{Results and Discussion}

In 1995, initial flower bud density was greater for 'Misty' (28) than for 'Sharpblue' (22). This concurs with field observations that 'Misty' usually initiates more flower buds than many other SHB cultivars. After treatment, flower bud density ranged from 7 to 34 in 'Misty' and from 5 to 27 in 'Sharpblue' in 1995 and from 5 to 35 in 'Misty' in 1997.

In 1995, 50\% bloom occurred on 9 Mar. for both 'Misty' and 'Sharpblue' and $80 \%$ bloom occurred on 19 Mar. and 23 Mar. for 'Misty' and 'Sharpblue', respectively. In 1997, 50\% bloom was reached on $23 \mathrm{Feb}$. and $80 \%$ bloom on $28 \mathrm{Feb}$. Since floral budbreak and fruit set overlapped and fruit density was not adjusted in this study, separation of the effects of flower bud density from the effects of fruit density was not possible. Fruit density increased with increasing flower bud density in both 'Misty' and 'Sharpblue', and in 1995 it was similar for both cultivars (Fig. 1).

The number of vegetative buds that broke and grew per unit cane length decreased as flower bud density increased, although flower bud density explained only $\approx 30 \%$ of the variability in vegetative budbreak (Fig. 2). This relationship was similar at all measurement dates. In 1995, percentage vegetative budbreak decreased $\approx 60 \%$ and $\approx 50 \%$ for 'Misty' and 'Sharpblue', respectively, as flower bud density increased from $5 \mathrm{buds} / \mathrm{m}$ to $30 \mathrm{buds} / \mathrm{m}$. Similarly, in 1997, vegetative budbreak in 'Misty' was reduced $\approx 75 \%$ at high (40 buds/ m) vs. low (5 buds/m) flower bud density. Although suppression of vegetative growth due to fruiting has been reported in several different species (Hurd et al., 1979; Maggs, 1963; Schecter et al., 1994), few, if any, reports exist on the effect of flower or fruit density on initial vegetative budbreak. The number of new vegetative shoots was greater for 'Sharpblue' than for 'Misty', indicating that cultivar also has a large effect on vegetative response to flower bud density. This cultivar effect may partially reflect differing budbreak phenologies.

The reduction in vegetative budbreak as flower bud density increased reduced total leaf area at final fruit harvest (Fig. 3A). New stem length and weight, as well as leaf weight, also decreased as flower bud density increased; however, because the $r$ values between leaf area, leaf dry weight, new stem length, and new stem dry weight were $>0.93$ for both

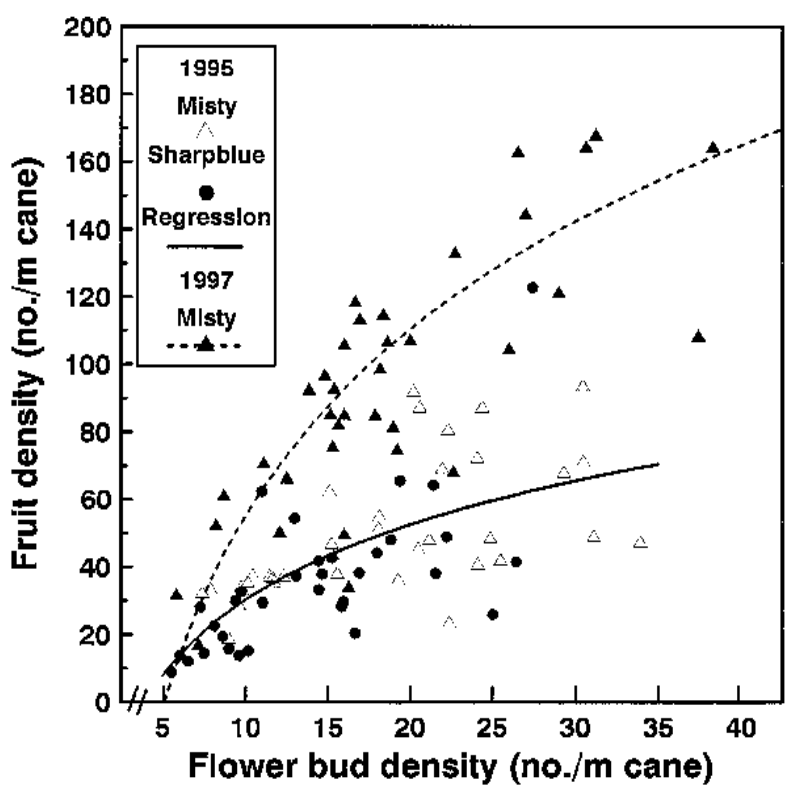

Fig. 1. Fruit density and flower bud density in 'Misty' and 'Sharpblue' SHB. 1995: $y=-0.43+0.32 \ln x, r^{2}$ $=0.45, P<0.001 ; 1997: \mathrm{y}=-1.27+0.78 \ln \mathrm{x}, r^{2}=0.66, P<0.0001$.

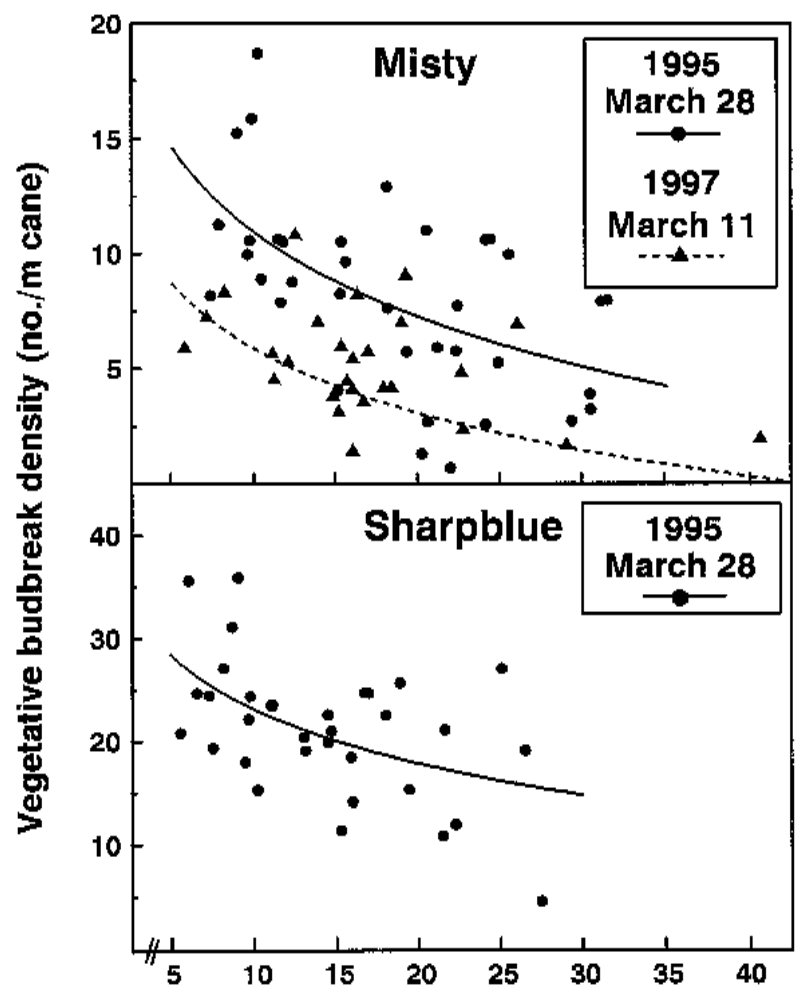

Flower bud density (no./m cane)

Fig. 2. Vegetative budbreak of 'Misty' and 'Sharpblue' SHB as affected by flower bud density. 'Misty', 28 Mar. 1995: $\mathrm{y}=0.257-0.053 \ln x, r^{2}=0.31, P<0.001$; 'Sharpblue', 28 Mar. 1995: $\mathrm{y}=0.386-0.089 \ln \mathrm{x}$, $r^{2}=0.34, P<0.001$; 'Misty', 11 Mar. 1997: $\mathrm{y}=0.151-0.0391 \mathrm{lnx}, r^{2}=0.36, P<0.0001$.

cultivars in 1995 and >0.94 in 1997, only leaf area is presented. Total leaf area was decreased $\approx 30 \%$ ('Sharpblue') and $\approx 40 \%$ ('Misty') in 1995 at high (30 buds/m) vs. low ( 5 buds/m) flower bud density. In 1997, total leaf area of 'Misty' was reduced $\approx 60 \%$ as flower bud density increased from 5 to 40 buds $/ \mathrm{m}$. These reductions in SHB are more dramatic than those reported for apple (Maggs, 1963; Schechter et al., 1994), strawberry
(Schaffer et al., 1986), and pistachio (Weinbaum et al., 1994). In these crops, however, some leaf area is already present when floral budbreak and fruit set occur, thus total leaf area is less likely to be negatively affected than in crops such as SHB where floral budbreak precedes ('Misty') or coincides with ('Sharpblue') vegetative budbreak. The phenology of budbreak in sweet cherry is somewhat more analogous to that in SHB, since 
floral and vegetative budbreak occur simultaneously. Even so, leaf area at fruit harvest was only $\approx 13 \%$ less on fruiting than on nonfruiting trees (Kappel, 1991). The larger reduction in leaf area of blueberry relative to sweet cherry may be due to the higher harvest index in blueberry (Darnell and Birkhold, 1996) or to the fact that new vegetative growth competes better with fruit growth in sweet cherry than in blueberry.

The reduction in total leaf area and the concomitant reduction in leaf area : fruit ratios with increased flower bud density (Fig. 3B) adversely affected fruit development. The mean fruit fresh weight decreased with decreasing leaf area : fruit ratio, particularly in 'Misty' (Fig. 4). Similar results have been reported for many other fruit crops, including apple (Ferree and Cahoon, 1987), peach (Weinberger, 1931), and cherry (Facteau et al., 1983; Roper and Loescher, 1987). In northern highbush blueberry, where leaf development begins prior to floral budbreak, berry size decreased with an increase in crop load, although specific leaf area : fruit ratios were not given (Ballinger et al., 1963). A leaf area : fruit ratio of $20 \mathrm{~cm}^{2}$ per fruit was needed for optimum fruit size in 'Tifblue' rabbiteye blueberry (Vaccinium ashei Reade) (Patten and Neuendorff, 1989). This is similar to results from our study for 'Sharpblue'. For 'Misty', however, the range in leaf area : fruit ratio was only 0 to $\approx 25 \mathrm{~cm}^{2}$ per fruit, and the lack of data points above this makes it difficult to predict if increased ratios would increase fruit fresh weight.

Fruit soluble solids increased as leaf area : fruit ratio increased in 'Misty', and to a lesser extent, in 'Sharpblue' (Fig. 5A). Similar increases in soluble solids as the leaf area : fruit ratio increased have been found for apple (Facteau et al., 1983; Ferree and Cahoon, 1987), sweet cherries (Roper and Loescher, 1987), and northern highbush blueberries (Ballinger et al., 1963). Regardless of the leaf area : fruit ratio, 'Sharpblue' fruit always had higher soluble solids than 'Misty' fruit. This, again, may be partially due to the difference in budbreak phenologies between the two cultivars.

Leaf area : fruit ratio did not affect FDP in 'Sharpblue'; however, there was a marked decrease in FDP with increased leaf area : fruit ratio in 'Misty' (Fig. 5B). Similarly, Ballinger et al. (1963) found that the FDP in 'Wolcott' blueberry decreased with a decrease in crop load, although actual FDP values were not given. Although no differences in FDP were found with 'Sharpblue' in our study, Patterson (1997) estimated that the last $25 \%$ of the fruit on heavily cropped 'Sharpblue' would be too small and late maturing to be marketable.

Flower and fruit thinning often reduce total fruit yield (Ballinger et al., 1963; Snelgar et al., 1986; Weinberger, 1931). This was true for 'Sharpblue' at all harvest dates, and final cumulative yield in 'Sharpblue' decreased from 235 to $53 \mathrm{~g}$ per cane as flower bud density decreased from 27 to 5 . However, in 1995 , cumulative fruit yield in 'Misty' through 10 May increased from 57 to $121 \mathrm{~g}$ per cane as flower bud density decreased from 34 to 7 . By

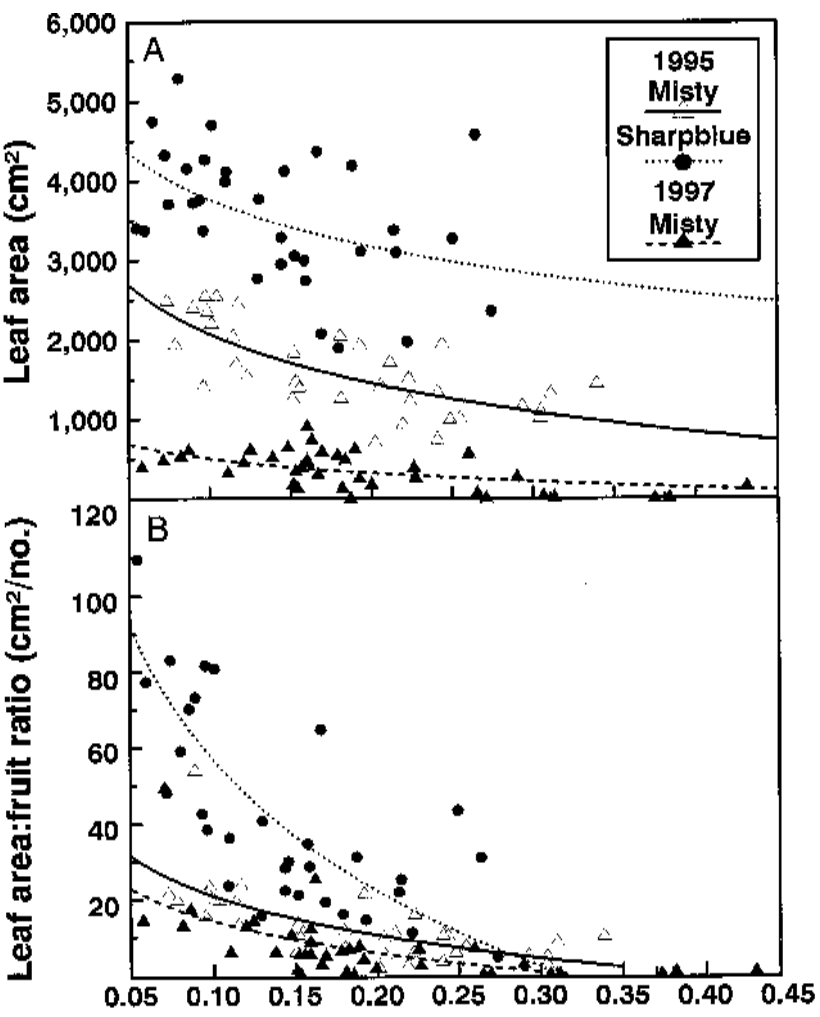

Flower bud density (no./cm cane)

Fig. 3. Total leaf area (A) and leaf area : fruit ratio (B) at final fruit harvest of 'Misty' and 'Sharpblue' SHB as affected by flower bud density. (A) 'Misty', 1995: $\mathrm{y}=2771-908 \ln \mathrm{x}+4.4$ length, $r^{2}=0.77, P<0.001$; 'Sharpblue', 1995: $\mathrm{y}=2982-858 \ln x+8.6$ length, $r^{2}=0.80, P<0.01$; 'Misty', 1997: $\mathrm{y}=880.2-287 \ln \mathrm{x}$ + 2.9length, $r^{2}=0.33, P \leq 0.0009$. (B) 'Misty', 1995: $\mathrm{y}=56.78-15.5 \operatorname{lnx}, r^{2}=0.47, P<0.001$; 'Sharpblue', 1995: $\mathrm{y}=164.7-45.4 \ln x, r^{2}=0.29, P<0.001$; 'Misty', 1997: $\mathrm{y}=42.8-12.4 \ln \mathrm{x}, r^{2}=0.41, P<0.0001$. The regression lines and data points shown indicate adjustment at the average value of the cane length covariate.

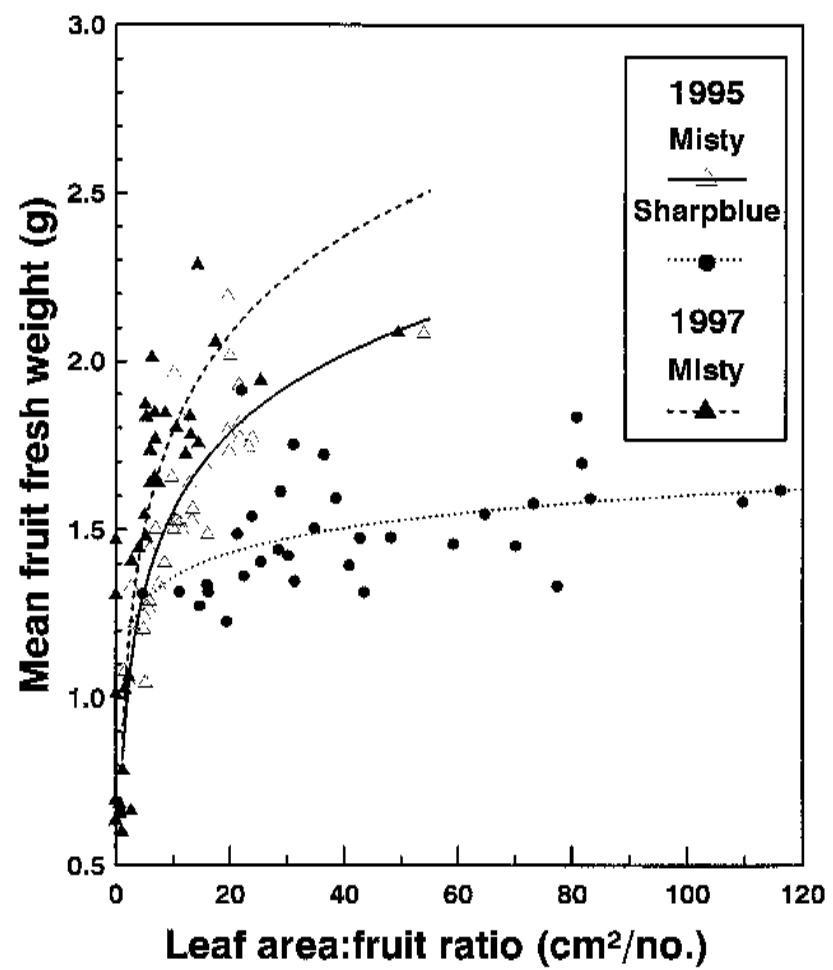

Fig. 4. Mean fruit fresh weight of 'Misty' and 'Sharpblue' SHB as influenced by leaf area : fruit ratio. 'Misty', 1995: $\mathrm{y}=0.78+0.34 \operatorname{lnx}, r^{2}=0.74, P<0.001$; 'Sharpblue', 1995: $\mathrm{y}=1.11+0.11 \ln x, r^{2}=0.21$, $P<0.01$; 'Misty', 1997: y = 0.83 + 0.421nx, $r^{2}=0.82, P<0.0001$. 


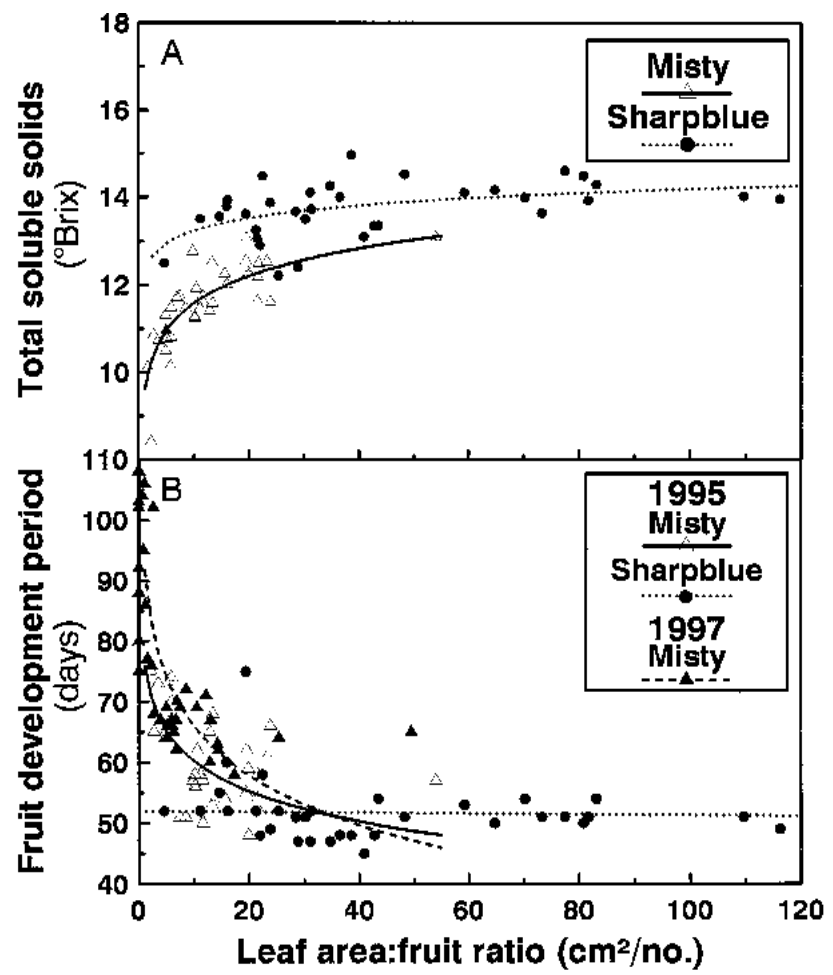

Fig. 5. Total fruit soluble solids (A) and fruit development period (B) of 'Misty' and 'Sharpblue' SHB as affected by leaf area : fruit ratio. (A) 'Misty', 1995: $\mathrm{y}=9.4+0.9 \operatorname{lnx}, r^{2}=0.39, P<0.0001$; 'Sharpblue', 1995: $\mathrm{y}=12.3+0.4 \ln x, r^{2}=0.39, P<0.0001$; (B) 'Misty', 1995: y = 76.8 - 7.2lnx, $r^{2}=0.36, P<0.001$; 'Sharpblue', 1995: Ns; 'Misty', 1997: y = 93.0 - 11.7lnx, $r^{2}=0.63, P<0.0001$. Data points for soluble solids are means for fruit sampled from each cane.

16 May, cumulative berry yield was similar for all flower bud densities, but by 30 May, cumulative yield had decreased from 194 to $140 \mathrm{~g}$ per cane as flower bud density decreased from 34 to 7 . The positive effect of flower bud thinning on early yield in 'Misty' was even more pronounced in 1997. Although final cumulative yield (through 30 May) was unaffected by flower bud thinning, cumulative yield through 13 Mar. increased from 39 to $216 \mathrm{~g}$ per cane as flower bud density decreased from 35 to 5 . Blueberry prices are always highest during the early harvest period, and flower bud thinning markedly increased early yield in 'Misty' in both years, with little, if any, detrimental effect on total cumulative yield.

These results indicate that decreasing flower bud density of some SHB cultivars increases vegetative development, resulting in an increase in fruit size and quality and an advancement in ripening. This appears to be especially true for those cultivars (i.e., 'Misty') that exhibit floral prior to vegetative budbreak, since early fruit development in these cases will depend solely on storage carbohydrates. In these cultivars, flower bud thinning would result in larger, earlier-season and higher- priced fruit. For example, 'Misty' may require that up to one-third of its flower buds be removed in order to stimulate vegetative budbreak and canopy and reproductive development. Although flower bud density and fruit density were not separated in this experiment, there appears to be an early effect of flower bud density, which may be critical for vegetative budbreak and development and warrants further investigation.

\section{Literature Cited}

Avery, D.J.,C.A. Priestley, and K.J. Treharne. 1979. Integration of assimilation and carbohydrate utilization in apple, p. 221-231. In: R. Marcelle, H. Clijesters, and M. Van Poucke (eds.). Photosynthesis and plant development. Dr. W. Junk, The Hague.

Ballinger, W.E., L.J. Kushman, and J.F. Brooks. 1963. Influence of crop load and nitrogen applications upon yield and fruit qualities of Wolcott blueberries. Proc. Amer. Soc. Hort. Sci. 82:264276.

Bell, H.P. 1950. Determinate growth in the blueberry. Can. J. Res. 28:637-644.

Birkhold, K.B., K.E. Koch, and R.L. Darnell. 1992. Carbon and nitrogen economy of developing rabbiteye blueberry fruit. J. Amer. Soc. Hort. Sci. 117:139-145.
Darnell, R.L. and K.B. Birkhold. 1996. Carbohydrate contribution to fruit development in two phenologically distinct rabbiteye blueberry cultivars. J. Amer. Soc. Hort. Sci. 121:1132-1136.

Facteau. T.J., N.E. Chestnut, and K.E. Rowe. 1983. Relationship between fruit weight, firmness, and leaf/fruit ratio in Lambert and Bing sweet cherry. Can. J. Plant Sci. 63:763-765.

Ferree, D.C. and G.A. Cahoon. 1987. Influence of leaf to fruit ratios and nutrient sprays on fruiting, mineral elements, and carbohydrates of apple trees. J. Amer. Soc. Hort. Sci. 112:445-449.

Forshey, C.G., R.W. Weirs, B.H. Stanley, and R.C. Seem. 1983. Dry weight partitioning of 'McIntosh' apple trees. J. Amer. Soc. Hort. Sci. 108:149-154.

Hurd, R.G., A.P. Gay, and A.C. Mountifield. 1979. The effect of partial flower removal on the relation between root, shoot and fruit growth in the indeterminate tomato. Ann. Appl. Biol. 93:77-89.

Kappel, F. 1991. Partitioning of above-ground dry matter in 'Lambert' sweet cherry trees with or without fruit. J. Amer. Soc. Hort. Sci. 116:201205.

Maggs, D.H. 1963. The reduction in growth of apple trees brought about by fruiting. J. Hort. Sci. 38:119-128.

Murneek, A.E. 1926. Effects of correlation between vegetative and reproductive functions in the tomato (Lycopersicon esculentum Mill.). Plant Physiol. 1:3-56.

Patten, K.D. and E.W. Neuendorff. 1989. Influence of light and other parameters on the development and quality of rabbiteye blueberry fruit, $\mathrm{p}$. 109-117. In: Proc. 1989 Texas Blueberry Growers Assn., Beaumont, Texas.

Patterson, K. 1997. A message from the president, p. 1-2. In: Blueberry News, Spring Issue. Florida Blueberry Growers Assn. Newsletter, Gainesville, Fla.

Roper, T.R. and W.H. Loescher. 1987. Relationships between leaf area per fruit and fruit quality in 'Bing' sweet cherry. HortScience 22:12731276.

Schaffer, B., J.A. Barden, and J.M. Williams. 1986. Whole plant photosynthesis and dry matter partitioning in fruiting and deblossomed day-neutral strawberry plants. J. Amer. Soc. Hort. Sci. 111:430-433.

Schechter, I., J.T.A. Proctor, and D.C. Elfving. 1994. Carbon exchange rate and accumulation in limbs of fruiting and nonfruiting apple trees. J. Amer. Soc. Hort. Sci. 119:150-156.

Snelgar, W.P., T.G. Thorp, and K.J. Patterson. 1986. Optimal leaf : fruit ratios for fruit growth in kiwifruit. Acta Hort. 175:115-120.

Weinbaum, S.A., G.A. Picchioni, T.T. Muraoka, L. Ferguson, and P.H. Brown. 1994. Fertilizer nitrogen and boron uptake, storage, and allocation vary during the alternate-bearing cycle in pistachio trees. J. Amer. Soc. Hort. Sci. 119:24-31.

Weinberger, J.H. 1931. The relation of leaf area to size and quality of peaches. Proc. Amer. Soc. Hort. Sci. 28:19-22.

Williamson, J.G. and P. Lyrene. 1995. Commercial blueberry production in Florida. Florida Coop. Ext. Serv., Inst. Food and Agr. Sci., Univ. Florida, Gainesville, SP 179. 